Rabaska

Revue d'ethnologie de l'Amérique française

LefebVRe, Solange (dir.). Le Patrimoine religieux du Québec.

Éducation et transmission du sens. Québec, Les Presses de

l’Université Laval, 2009, 416 p. ISBN 978-2-7637-8819-7

\title{
Cindy Morin
}

Volume 8, 2010

URI : https://id.erudit.org/iderudit/045285ar

DOI : https://doi.org/10.7202/045285ar

Aller au sommaire du numéro

Éditeur(s)

Société québécoise d'ethnologie

ISSN

1703-7433 (imprimé)

1916-7350 (numérique)

Découvrir la revue

Citer ce compte rendu

Morin, C. (2010). Compte rendu de [Lefebvre, Solange (dir.). Le Patrimoine religieux du Québec. Éducation et transmission du sens. Québec, Les Presses de l’Université Laval, 2009, 416 p. ISBN 978-2-7637-8819-7]. Rabaska, 8, 226-229.

https://doi.org/10.7202/045285ar d'utilisation que vous pouvez consulter en ligne.

https://apropos.erudit.org/fr/usagers/politique-dutilisation/ 
titre, au verso et à la fin du premier chapitre. Autre point faible, plusieurs membres des communautés mettent leurs espoirs dans l'engagement des laïcs afin de perpétuer leur œuvre. Pourtant, un seul laïc a participé aux entrevues. Finalement, il va de soi que chacune des communautés, tant masculines que féminines, ait voulu présenter ses membres dont l'accomplissement est exceptionnel. J'aurais personnellement apprécié le récit de vie de ces nombreux religieux aux humbles fonctions qui nous ont rendu la vie agréable. Je pense, entre autres, aux religieux affectés à l'entretien des locaux et particulièrement aux religieuses qui nous cuisinaient de si bons biscuits dont l'odeur reste gravée dans nos mémoires de collégiens et collégiennes ! Ces religieux au statut modeste devenaient souvent des confidents tant dans les écoles et les orphelinats que les hôpitaux. Je leur rends ici hommage.

En terminant, rappelons que, dès 2001, une étude réalisée par Samson, Bélair, Deloitte \& Touche (Projections démographiques. Rapport Sommaire, Ottawa, Conférence religieuse canadienne, 26 janvier 2001) prévoyait l'extinction complète des communautés religieuses du Québec d'ici 2035, si la tendance démographique observée se maintenait. Au moment de mettre sous presse, neuf membres de communautés religieuses, dont les propos ont été édités dans ce livre, étaient décédés. Rappelons qu'en mai 2009, le père Fernand Lindsay, clerc de Saint-Viateur, nous quittait, portant à dix le nombre de religieux disparus. Devant ce constat, nous pouvons nous demander quel serait la pertinence d'un deuxième volume portant sur la centaine de communautés religieuses n'ayant pas encore participé à une étude. Eu égard à cette remarque, je pense néanmoins que les communautés contemplatives auraient beaucoup à transmettre à notre société québécoise désormais séculière en recherche d'expériences spirituelles.

Carole Charbonneau

Université du Québec à Montréal

Lefebvre, Solange (dir.). Le Patrimoine religieux du Québec. Éducation et transmission du sens. Québec, Les Presses de l'Université Laval, 2009, 416 p. ISBN 978-2-7637-8819-7.

La Chaire religion, culture et société de la faculté de théologie et de sciences des religions de l'Université de Montréal, en collaboration avec la Fondation du patrimoine religieux du Québec, organisait en 2006 le colloque «Le patrimoine religieux du Québec : éducation et transmission du sens ». L'objectif du colloque était de poursuivre le débat et les réflexions sur le 
patrimoine religieux québécois dont les discussions avaient été entamées par la Commission des biens culturels du Québec lors des consultations publiques de 2005. Le colloque, qui a eu lieu du 22 au 24 novembre 2006, a donné lieu à la production d'une série télévisée diffusée au canal Savoir ainsi qu'à la préparation de cet ouvrage sous la direction de Solange Lefebvre, organisatrice du colloque et titulaire de la Chaire religion, culture et société de l'Université de Montréal.

Après une préface de Jocelyn Groulx, directeur de la Fondation du patrimoine religieux du Québec, et une introduction de Solange Lefebvre, le livre se divise en trois parties à la suite desquelles le lecteur trouvera la conclusion de Lefebvre ainsi qu'une bibliographie complète et la liste des auteurs et leurs affiliations. Les illustrations en couleur accompagnant les 22 articles sont rassemblées au centre du livre. Enfin, la présentation de sept initiatives locales complète l'ouvrage. Elles résultent de kiosques qui étaient aménagés lors du colloque afin de partager des expériences concrètes de transmission du patrimoine religieux avec les participants.

L'ouvrage met à contribution 26 auteurs provenant de milieux variés : universités, musées, communautés religieuses et organismes divers. La diversité des approches - théologique, ethnologique, philosophique, muséologique, historique - permet de proposer un éventail de points de vue sur la question de la transmission du patrimoine religieux québécois. Le patrimoine est abordé dans toutes ces composantes allant du général au particulier, autrement dit des grands enjeux aux études de cas spécifiques.

La première partie s'intitule "Visions du patrimoine religieux ». Elle est composée de sept textes qui définissent « les termes et les problématiques entourant la sauvegarde du patrimoine religieux au Québec et dans le monde » et qui contribuent « à étendre notre conception de ce qu'est le patrimoine religieux ». Plusieurs notions sont expliquées et divers enjeux sont soulevés en faisant un survol de la problématique générale et en posant d'emblée les pierres angulaires des réflexions sur le sujet. Mario Dufour propose un texte incontournable. Ainsi, après la définition des notions de patrimoine, de signification et de valeur ainsi qu'une chronologie des débats sur le sujet, il cible huit enjeux entourant la transmission du patrimoine religieux : 1- la connaissance de ce patrimoine ; 2- l'enseignement religieux aux jeunes ; 3- la formation des maîtres ; 4- la gestion des biens culturels matériels et du patrimoine immatériel afférent; 5- les ressources humaines et financières nécessaires ; 6- la mémoire ou l'importance de l'histoire du Québec ; 7- l'acceptation du changement; et 8- les divers usagers du patrimoine et la conciliation des valeurs.

La deuxième partie du livre, «Éduquer au patrimoine», est scindée en deux : les enjeux séculiers et les enjeux religieux. Les questions de la 
transmission du sens sont soulevées. En effet, comment léguer ces notions intangibles aux futures générations? D’entrée de jeu, Pierre Lucier propose d'aller au-delà du patrimoine et du religieux dans l'étude de l'intérêt du public pour le patrimoine religieux. En deçà de toute qualification religieuse, ce patrimoine est d'abord du patrimoine au sens large. Quant au sens religieux, il correspond à des significations culturelles collectives plus vastes qui, une fois connues et reconnues, peuvent être utilisées comme un outil de réflexion et de décision lors de la transformation des biens. En conclusion, il suggère que l'apprentissage du patrimoine religieux fasse partie d'une éducation culturelle plus vaste. En contrepartie, Maxime Allard affirme que la difficulté de transmettre le "patrimoine de communautés religieuses » vient, notamment, de la question de l'appropriation. S'approprier une chose religieuse revient à faire sien du religieux - ce qui peut être ardu pour une société laïque. Cela expliquerait pourquoi le patrimoine religieux est constitué plus souvent de lieux et d'objets que d'essence spirituelle. Ainsi perçus, ce que l'on nomme patrimoine religieux serait en fait davantage des traces de certains épisodes collectifs et, en ce sens, témoignerait plus d'un patrimoine socioculturel que d'un patrimoine religieux. En somme, et selon les mots d'Allard, la patrimonialisation et la muséification consisteraient à «mettre hors d'usage religieux [et] social » des lieux de vie, de prière et de célébration. Christine Cheyrou poursuit en ce sens en expliquant clairement les différents niveaux de sacralité en opération entre la pratique rituelle et la pratique muséale. Les institutions muséales sont présentées comme une sorte de temple où les objets sont considérés comme étant sacrés et bénéficient d'un statut particulier et même de certains rituels. Bien que les objets y soient préservés et explicités, ces institutions ne peuvent transmettre la sacralité des rites les entourant dans leur vie active.

« Histoires de transmission et de sauvegarde » est le titre de la dernière partie. Six textes font le point sur des expériences vécues, puis sept initiatives locales apportent la touche finale à cette section bien ancrée dans le quotidien de la transmission. À nouveau, le rôle des acteurs en présence dans les prises de décisions et les actions demeure capital. La transmission ne peut se faire sans un degré d'engagement de la part des personnes interpelées par ce patrimoine, qu'il s'agisse des hommes et des femmes liés aux communautés religieuses ou des citoyens et citoyennes côtoyant quotidiennement ou occasionnellement ces lieux, ces objets, ces biens matériels et les rituels les entourant.

Dans l'ensemble, cet ouvrage favorise la réflexion sur les enjeux entourant le patrimoine religieux. L'hétérogénéité des auteurs génère une complémentarité des points de vue permettant de bien cerner la question. Il 
s'agit d'un ouvrage important pour toute personne interpellée par les problématiques de la transmission du patrimoine religieux.

Cindy Morin

Consultante en patrimoine

Maligne, Olivier. Les Nouveaux Indiens. Une ethnographie du mouvement indianophile. Québec, Les Presses de l'Université Laval, « Intercultures », 2006, 288 p. ISBN 978-2-7637-8427-4.

L'ouvrage d'Olivier Maligne débute par un avertissement clair et primordial dont la première phrase affiche la couleur de l'étude : « Ce livre ne traite pas des autochtones d'Amérique du Nord, du moins pas directement. Ce livre traite en premier lieu de gens qui sont parfois appelés "indianistes" etc. ». L'étude annoncée ne rend donc pas grâce à un mouvement culturel, n'en fait pas une critique corrosive et n'est pas non plus le manuscrit d'un ethnologue devenu adepte de son sujet d'étude. Par son cadre théorique, cette réflexion nous plonge avant tout de façon objective et stimulante dans le monde méconnu et néanmoins passionnant de l'« indianophilie ».

À la lumière des travaux de Marc Augé, l'auteur souligne brillamment la condition actuelle de toute recherche ethnologique : «la contemporanéité des "mondes" sociaux, leur co-présence et leurs relations généralisées à la surface du globe etc. » (p. 12). Cependant, ce regard ethnographique impliquant une « perspective nouvelle » ne signifie pas l'uniformisation des formes culturelles. Bien au contraire, l'auteur va ici nous faire part d'un de ces mondes qui doute peut-être plus de sa propre existence que celles des autres dans l'exercice de sa reconnaissance. Ainsi à travers ces formes contemporaines de la culture et de l'identité, Maligne présente le « bricolage » culturel (terme emprunté à Claude Lévi-Strauss) qu'effectue un « indianophile», qui se trouve être une personne d'origine non indienne, mais qui désire cependant vivre comme un Amérindien.

L'ethnographie du monde indianophile se dévoile au fil des pages, comme une véritable réflexion anthropologique fondamentale lorsque se dégagent les réalités que recouvrent les termes de " culture », "identité », " mythe » ou encore " univers » afin de ne pas commettre d'impairs dans l'esprit du lecteur lambda. Il s'agit alors de comprendre les enjeux de ces définitions terminologiques dans la société, tant pour les spécialistes de culture traditionnelle que pour les amateurs.

En premier lieu, la définition générique de l'indianophilie s'élabore grâce 